\title{
Is a Nuclear Deal with Iran Possible? An Analytical Framework for the Iran Nuclear Negotiations
}

\section{Citation}

Sebenius, James K., and Michael K. Singh. "Is a Nuclear Deal with Iran Possible? An Analytical Framework for the Iran Nuclear Negotiations." International Security 37, no. 3 (Winter 2012): 5291.

\section{Published Version}

http://www.mitpressjournals.org/doi/abs/10.1162/ISEC_a_00108

\section{Permanent link}

http://nrs.harvard.edu/urn-3:HUL.InstRepos:10578868

\section{Terms of Use}

This article was downloaded from Harvard University's DASH repository, and is made available under the terms and conditions applicable to Open Access Policy Articles, as set forth at http:// nrs.harvard.edu/urn-3:HUL.InstRepos:dash.current.terms-of-use\#OAP

\section{Share Your Story}

The Harvard community has made this article openly available.

Please share how this access benefits you. Submit a story.

\section{Accessibility}




\title{
Is a Nuclear Deal with Iran Possible?
}

\section{An Analytical Framework for the Iran Nuclear Negotiations}

\author{
James K. Sebenius
}

and

Michael K. Singh

November 2012

(forthcoming in International Security, Vol. 37, No. 3, Winter 2012/2013)

James K. Sebenius is a professor at the Harvard Business School and Director of the Harvard Negotiation Project. Michael K. Singh is the managing director of the Washington Institute for Near East Policy.

Without implicating others in the analysis or conclusions of this article, the authors are deeply grateful for the deliberations and feedback of the members of the Iran Negotiations Working Group at the Belfer Center for Science and International Affairs at Harvard University, c-chaired by Graham Allison and James Sebenius: Matthew Bunn, Joseph Costa, Olli Heinonen, David Lax, Martin Malin, Rolf Mowatt-Larssen, Jacqueline Newmyer, and William Tobey. 


\begin{abstract}
Varied diplomatic approaches by multiple negotiators over several years have failed to conclude a nuclear deal with Iran. Mutual hostility, misperception, and flawed diplomacy may be responsible. Yet, more fundamentally, no mutually acceptable deal may exist. To assess this possibility, a "negotiation analytic" framework conceptually disentangles two issues: 1) whether a feasible deal exists and 2) how to design the most promising process to achieve one. Focusing on whether a "zone of possible agreement" exists, a graphical negotiation analysis precisely relates input assumptions about the parties' interests, their no-deal options, and possible deals. Under a plausible, mainstream set of such assumptions, the Iranian regime's nodeal options, at least through summer 2012, appear superior to potential nuclear agreements. If so, purely tactical and process-oriented initiatives will fail. Opening space for a mutually acceptable nuclear deal-that avoids both military conflict and a nuclear-armed or nuclearcapable Iran-requires relentlessly and creatively worsening Iran's no-deal options while enhancing the value to Iranian regime of a "yes." Downplaying both coercive options and upside potential, as international negotiators have often done, works against this integrated strategy. If this approach opens a zone of possible agreement, sophisticated negotiation will be key to reaching a worthwhile agreement.
\end{abstract}




\section{Is a Nuclear Deal with Iran Possible?}

\section{An Analytical Framework for the Iran Nuclear Negotiations}

Since assuming the presidency of the United States in January 2009, Barack Obama has tried both outreach and sanctions in an effort to halt Iran's progress toward a nuclear weapons capability. Yet neither President Obama's personal diplomacy nor several rounds of talks between Iran and the five permanent members of the United Nations Security Council - China, France, Russia, the United Kingdom, and the United States - plus Germany (the "P5+1") nor escalating sanctions have deterred Tehran. Iran has not only continued but accelerated its nuclear progress, accumulating sufficient low-enriched uranium that, if further enriched, would be sufficient for five nuclear weapons. ${ }^{1}$ Consequently, as Iran makes major advances in its nuclear capabilities, speculation has increased that Israel or a United States-led coalition may be nearing the decision to conduct a military strike to disable Iran's nuclear program.

Analysts and policymakers have offered various explanations for the failure to make progress toward a negotiated resolution to the nuclear dispute with Iran. A survey of these explanations would surface a multitude of barriers to a nuclear agreement - decades of hostility and estrangement, domestic politics on both sides, poor tactics and missed opportunities, to name a few. ${ }^{2}$ Indeed, U.S. tactics with respect to the Iran nuclear negotiations became a major point of

\footnotetext{
${ }^{1}$ For a further technical discussion of Iran's nuclear progress, see, for example, David Albright, Andrea Stricker, and Christina Walrond, "ISIS Analysis of IAEA Iran Safeguards Report," (Washington, D.C.: Institute for Science and International Security, May 25, 2012), http://isis-online.org/uploads/isisreports/documents/ISIS Analysis IAEA Report 25May2012.pdf.

2 See, for example, John Limbert, Negotiating with Iran: Wrestling the Ghosts of History (Washington, D.C.: United States Institute of Peace Press, 2009; Trita Parsi, A Single Roll of the Dice: Obama's Diplomacy with Iran. (New Haven, Conn.: Yale University Press, 2012); and Barbara Slavin, "Engagement," in Jon B. Alterman, ed., Gulf Kaleidoscope: Reflections on the Iranian Challenge (Washington, D.C.: Center for Strategic and
} 
contention in the 2008 U.S. presidential campaign, with candidate Barack Obama stressing engagement and candidate John McCain emphasizing sanctions and force.

Amid this preoccupation with diplomatic processes — whether to offer a bottom-line deal or a phased agreement, whether to seek a grand bargain or a narrow understanding, whether to declare a deadline for talks or not, whether to deal directly or through intermediaries, whether "front" or back channels are more promising, whether a multilateral (P5+1) or bilateral U.S.-Iran format would be better, and so on - a more fundamental issue has become obscured: Is there any outcome to the nuclear crisis upon which Iran and the United States could both agree? The inability of multiple international negotiators, via a variety of diplomatic processes, to conclude a nuclear deal with Iran raises the possibility that no deal has been feasible over the course of the negotiations, at least through the fall of 2012. This article seekd to separate the question of whether a mutually acceptable deal is possible from the question of the most promising diplomatic processes and tactics to reach a worthwhile deal.

This is a distinction that in more routine contexts is intuitively familiar. For example, if you are seeking to buy a house and have an absolute upper limit of $\$ 400,000$, but the current owner of the house-who cares solely about price- has another credible offer for $\$ 500,000$, no deal is possible, regardless of your negotiating skill or bargaining approach. If, on the other hand, the house's owner has a credible offer of $\$ 375,000$, a deal with you is possible, but by no means inevitable. Whether it is reached and what price is agreed-from $\$ 375,000$ to $\$ 400,000$ - depends on the negotiating tactics of both parties. Likewise, if the minimum nuclear capability the Iranian

International Studies, May 2012), pp.11-21. 
regime is willing to accept exceeds the maximum the United States will tolerate, no nuclear deal is possible absent steps to bridge this divide.

In negotiating parlance, whether a deal is feasible (i.e., mutually acceptable) is said to depend on the existence of a "zone of possible agreement" (ZOPA). A ZOPA is the range of potential deals that are better in terms of each party's perceived interests than the best alternative to a negotiated agreement (or "no-deal option") of each party.

Sometimes no-deal options consist of alternative offers or their absence (as in the houseselling example above); in other cases, no-deal options entail different consequences of walking away. For example, refusing to settle a lawsuit normally implies (facing the no-deal option of) going to court, with its attendant costs and risks. A firm's no-deal option in union bargaining will often be a strike. Failing to come to agreement with one potential alliance partner may lead to negotiations with another, or simply going it alone. In these examples, there might be no ZOPA in the initial negotiation, if one side were, respectively, absolutely convinced it would prevail in court (in the lawsuit example), believed it would quickly and costlessly break a strike (in the union bargaining example), or judged that it would find an even more appealing alliance partner quickly or do better alone (in the alliance negotiation example). ${ }^{3}$ Opening up a ZOPA would require actions to alter these perceptions, often by changing the underlying realities. Across these and more complex cases, a necessary—but not sufficient—condition for each party's reaching agreement is that the deal appear superior, in terms of each party's subjectively perceived interests, to its best no-deal option.

${ }^{3}$ There is no assumption or expectation in the analysis that perceptions of a ZOPA are common knowledge or that the sides have "perfect information." In fact, the essence of many negotiating situations is uncertainty over the existence, let alone the scope and dimensions, of a ZOPA. Typically, each side has a view of its own limits (implying "its end" of the ZOPA), but faces considerable uncertainty about that of the other. 
To explore whether a nuclear deal with Iran is possible — that is, whether a ZOPA exists this article introduces a simple analytical framework designed to visualize the ZOPA and therefore the range of feasible deals, and how they would be affected by different assumptions and policy choices. In essence, the framework offers a means of displaying whether a deal exists that is simultaneously better for both sides than their most likely no-deal options.. The major contribution of this article is, in a sense, the framework itself — that is, a format to separately assess the distinct elements of the Iran nuclear negotiations, to make deliberate assessments with regard to each of them, and put them in proper analytic relationship to each other in order to draw valid conclusions and make more effective policy decisions. Prescriptively, this approach indicates the complementary roles of cost-imposing and value-enhancing moves in opening space for a potential deal.

In particular, discussions of the Iran nuclear negotiations often confuse, artificially separate, or conflate several relevant factors that, when properly considered, bear a precise relationship to each other and, together, determine the underlying potential for a deal. These include each side's interests, each side's no-deal option (and implied minimum acceptable conditions for a deal), each side's stated bargaining position, the range of possible agreements, actual or threatened costs, as well as actual or promised incentives and benefits. It is easy, for example, for analysts to compartmentalize sanctions, military activities and threats of coercive measures, and other costimposing moves as somehow independent from "negotiation" and possible value-creating options. The framework developed in this article offers the potential to unify these often-separate elements into a coherent negotiating strategy. 
It is frequently asserted that negotiating with the Iranian regime is not unlike haggling in the carpet bazaars of Tehran, where one must keep one's wits or be outsmarted by the savvy merchants. No wiles, however, will help the poor carpet consumer whose best offer is less than the price that the merchant can rapidly and confidently get from another buyer. More generally, if one party sees walking away (no-deal) as better than any deal potentially on offer by the other, agreement will not be struck. For Iran and the United States, the fundamental challenge for negotiation is finding an agreement that is better — in the eyes of both parties - than the two most likely no-deal options: war or an Iran armed with nuclear capabilities. The existence of a ZOPA is a prerequisite for diplomatic success by whatever process. If no such zone of possible agreement can be created, then the alternatives, however unpalatable, must be considered.

At the time of this writing, overt negotiations between Iran and the P5+1 were on hold, despite reports that they might resume after the U.S. presidential election. Sanctions were being tightened, and the possibility of coercive action was increasingly discussed and demonstrated. However this issue evolves over time, the framework developed in this article for assessing whether a zone of possible agreement exists—and the classes of measures necessary to create or widen a ZOPA—should prove to be useful input to the use and design of diplomatic processes in many issue domains.

The next section qualitatively develops the basic logic of this approach along with appropriate caveats. To develop first-order implications of the framework, this qualitative introduction posits and discusses a mainstream set of policy "input assumptions" about each side's interests and no-deal options as well as potential deals. The following section takes the analysis further, visually illustrating the existence and location of a ZOPA, or its absence, in U.S.-Iranian 
nuclear dealings. The graphical analysis also shows the effects on a ZOPA of various cost-imposing and value-enhancing measures. While the framework, whether expressed qualitatively or graphically, is robust to a wide range of policy assumptions, we show that, under a fairly mainstream set of policy views, it is unlikely that a ZOPA exists as of this writing. The next section discusses in greater detail the characteristics required of cost-imposing and value-enhancing moves to open up a ZOPA. Following an assessment, using this framework, of past negotiating efforts under U.S. Presidents George W. Bush and Barack Obama, the final section offers conclusions and recommendations.

\section{A Simple Analytical Framework: Qualitative Introduction}

Much of the popular discussion of negotiations, whether on the Iran nuclear issue or other topics, centers on tactics and process. Examples include whether to employ intermediaries or deal directly, negotiate with counterpart officials or through back channels, employ a multilateral or bilateral format in talks, operate publicly or in secret, seek to deeply empathize with differences of culture and perception or let issues speak for themselves, engage in small talk and relationship building or get straight to the point, bully or charm, show one's cards or keep them close to the vest, focus early on guiding principles or on specifics, start with exaggerated demands or more reasonable ones, seek to build momentum by tackling easy issues first, press hard for early closure via deadlines or let the process proceed at a more relaxed pace, and so on.

Such "at-the-table" matters are not trivial, but they are only one "dimension" of a fuller, "three dimensional (3D)" approach to negotiation analysis. ${ }^{4}$ Beyond tactics, the second dimension

\footnotetext{
${ }^{4}$ For a fuller, relatively accessible description of the methodological approach implicit in this article, see
} David A. Lax, and James K. Sebenius. 3D Negotiation (Boston: Harvard Business School Press, 2006). For more 
is deal design - that is, creatively structuring potential agreements so that they maximize value for all parties and prove sustainable. The third, more "architectural," dimension is the underlying "setup" of the negotiation — that is, the parties, their interests and no-deal options, the sequence of approach, and actions to shape those factors to increase the likelihood of a successful outcome once the parties arrive at the table. In this article's "negotiation analytic" framework, we move away from the tactical dimension and focus on the setup and deal design dimensions, especially the parties, interests, and no-deal options in the context of potential deals.

Specifically, we seek to address the first two of what we believe are three critical questions facing U.S. policymakers on Iran. First, within the existing setup, is any mutually acceptable deal possible, given each side's perception of its interests and no-deal options? That is, is there, as of this writing, a zone of possible agreement on nuclear issues between the U.S. government and the hard-line Iranian regime? Second, if not, can moves to change the setup or deal design alter one or both party's calculations to make a deal feasible, that is, to create a ZOPA? The third question, not addressed here, pertains to those tactical and process choices that would be most likely to realize a deal, were one feasible.

technically minded readers, the "negotiation analytic" methodology adopted in this article lies between conventional game theory and decision analysis. See James K. Sebenius, "Negotiation Analysis: A Characterization and Review," Management Science, Vol. 38, No. 1 (January 1992), pp. 1-21; and Howard Raiffa, John Richardson and David Metcalfe, Negotiation Analysis: The Science and Art of Collaborative Decision Making (Cambridge, Mass.: Belknap Press of Harvard University Press, 2002). For an updated account, see James K. Sebenius, "Negotiation Analysis: Between Decisions and Games," in Ward Edwards, Ralph Miles, and Detlof von Winterfeldt, eds., Advances in Decision Analysis (Cambridge: Cambridge University Press, 2007), pp. 469-488. For this approach applied more specifically to international negotiation problems, see James K. Sebenius, "Challenging Conventional Explanations of Cooperation: Negotiation Analysis and the Case of Epistemic Communities," International Organization, Vol. 46, No. 1 (Winter 1992), pp. 323-365; and James K. Sebenius, "International Negotiation Analysis," in Victor Kremenyuk, ed., International Negotiation: Analysis, Approaches, Issue, 2d ed. (San Francisco, Calif.: Jossey-Bass, 2002), 229-252. 


\section{Caveats}

Some advance caveats are in order, given the purposeful simplicity of this framework. We consciously focus the bulk of our attention on the official U.S.-Iranian nexus given its central importance to this policy area. Obviously, however, nuclear negotiations involve a range of players such as the other P5+1 parties, Israel, and the Arab states, each of which has its own interests and no-deal options. In addition, the United States and Iran themselves are hardly monolithic, but rather are composed of internal parties such as, on the U.S. side, the White House, Congress, and various partisan factions. Preferences and interests are sensible, especially in a political context as riven with divisions as Iran's, only to the extent they are understood "factionally." The presentation of incentives or imposition of costs on Iran by the United States involves complex negotiations with these external and internal parties. It is entirely possible that the failure of these negotiations could result in one side being blocked by an internal party from exploiting a ZOPA if it opens. In fact, this may have been what occurred in October 2009, when Iranian negotiators in Vienna appeared to agree to a nuclear fuel swap, only to have it scuppered by leaders in Tehran. We do not explore such internal negotiations in this article, but they are implicitly represented-not ignored-by the framework we present.

In light of these caveats, a fuller negotiation analysis would build on the framework presented in this article to probe important related questions such as: (1) the most effective ways to manage each side's challenging "internal" negotiations "on its own side of the table," including potentially complex U.S.-Israeli interactions, as well as how U.S. moves could affect the internal Iranian negotiations and vice versa; (2) how best to negotiate potential durable coalitions of parties as diverse as China, Israel, Russia, the European Union (EU), and the Gulf Arab states that could 
tighten sanctions (or other costs) on Iran, provide incentives to it, or both; (3) how to counter ongoing and future moves by Iran intended to divide or weaken potentially adverse coalitions of parties; and (4) the relationship between early conciliatory moves for engagement and building wider support for possible later moves, if necessary, to confront Iran more forcefully.

A further set of caveats is in order. Even within our relatively simple two-party setup, valuations and preferences - relative as well as absolute — and no-deal options are often vague, frequently contested among analysts and policymakers alike, and are shaped by distrust and partisan perceptions. This article presents an assessment of how Iranian and U.S. decisionmakers perceive their interests and no-deal options, but it is vital to note that these assessments, and more important each side's perceptions of the other, are only as good as the available information and interpretations.

Finally, we assume, as does the U.S. intelligence community, that “Iran's nuclear decisionmaking is guided by a cost-benefit approach." ${ }^{5}$ This neither implies perfect rationality or perfect information, nor does it assume that Iranian leaders' valuation of costs and benefits resembles that of the United States. ${ }^{6}$ Rather, it assumes that the regime acts in a roughly purposeful fashion to advance its interests as best it sees fit. ${ }^{7}$ As such, understanding how the regime assesses its interests and no-deal options is vital to predicting behavior.

${ }^{5}$ David Blair, U.S. Intelligence Community Annual Threat Assessment, statement, for the record for the Senate Elect Committee on Intelligence, Washington, D.C., February 2, 2010.

${ }^{6}$ For an extended discussion of the issue of whether the Iranian regime is "rational," see Michael Singh, "Is the Iranian Regime Rational?," Foreign Policy, February 23, 2012, http://www.washingtoninstitute.org/policyanalysis/view/is-the-iranian-regime-rational.

${ }^{7}$ We are fully aware of the roles that misperception, miscalculation, "irrational" escalation, emotion, and the like can play in negotiation - and the extensive literature on these subjects. A (weakly) rational baseline, however, such as this paper provides, remains useful for analysis-with such factors later incorporated as appropriate. 
With these caveats in mind, the analytical framework we employ to address these questions requires a few basic "inputs" or policy assumptions about the parties' key interests and no-deal options, as well as potential agreements. Although a range of creative options might be envisioned, with many possible provisions and linkages to issues such as trade and energy development, we initially focus on outcomes or deals limited to nuclear issues of central concern to policymakers. (The analysis later brings in broader, nonnuclear issues as potential deal ingredients.) Moving from the most "U.S.-favoring" to the most "Iran-favoring" possibilities, these potential agreements include a rollback of the Iranian nuclear program, a freeze of Iran's uranium-enrichment activities, strong restrictions on enrichment, weak restrictions on enrichment, nuclear "latency," actual weaponization, and an Iran with many warheads and missile delivery systems. Associated with each of these outcomes are monitoring and enforcement provisions, which do not necessarily vary in a linear fashion from one outcome to the next (i.e., it is not necessarily the case that a more restrictive outcome requires more monitoring and vice versa).

\section{U.S. AND IRANIAN INTERESTS}

Beyond potential deals, the analysis also requires an assessment of each side's interests. In the U.S. case, these can be drawn largely from officials' own statements, whereas in the case of the Iranian regime, they must be inferred from actions, behavior, and the numerous studies on the regime's ideology. ${ }^{8}$ While the assessments below are mainstream and widely held by the U.S. and allied governments, one strength of the analytical framework discussed below is its openness to a wide

\footnotetext{
${ }^{8}$ For a particularly useful study of the attitudes of Iranian Supreme Leader Ayatollah Ali Khamenei, see Karim Sadjadpour, Reading Khamenei: The World View of Iran's Most Powerful Leader (Washington, D.C., Carnegie Endowment for International Peace, 2009), http://carnegieendowment.org/files/sadjadpour iran final2.pdf.
} 
range of possible assumptions that reflect different points of view and thus different implications for the negotiations.

First, our analysis assumes that Iran, or more precisely, the hard-line Iranian regime, has a keen interest in and is pursuing a nuclear weapons capability. This reflects the judgment of the U.S. intelligence community, ${ }^{9}$ and can reasonably be inferred from the collection of nuclear activities in which Iran is engaged: fuel fabrication, weaponization research, and missile delivery systems, which together are the key components of a nuclear weapon. We do not assume, however, that Iran will build a nuclear weapon, though this obviously is a possible outcome.

Although Iran has consistently denied its interest in acquiring nuclear weapons or the capability to produce them, many observers judge that Iran places a high priority on a nuclear weapons capability given its defiance of Security Council resolutions, its failure to satisfy concerns voiced by the International Atomic Energy Agency (IAEA), and its history of concealed facilities. ${ }^{10}$ More broadly, the Iranian regime's overriding interests appear to be its own survival and the persistence of the current velayat-e faqih system of government ("guardianship of the religious jurist" or absolute power of a ruling cleric). The development of a nuclear weapon would serve these interests by acting as a deterrent, a fact openly acknowledged by Iranian officials in the late

\footnotetext{
${ }^{9}$ For example, in his 2012 briefing to the Senate, Director of National Intelligence James Clapper stated: "We assess Iran is keeping open the option to develop nuclear weapons, in part by developing various nuclear capabilities that better position it to produce such weapons, should it choose to do so." Clapper, Worldwide Threat Assessment of the U.S. Intelligence Community, unclassified statement for the record for the Senate Elect Committee on Intelligence, Washington, D.C., January 31, 2912, p. 5, http://intelligence.senate.gov/120131/clapper.pdf.

${ }_{10}$ Residual doubts are fairly commonly expressed by credible outsiders as well. For example, Yukiya Amano, the U.S.-backed head of the International Atomic Energy Agency, was forthright in an interview criticizing Iran's failure to cooperate or answer critical questions about highly suspicious activities. Yet he stated, "Despite all unanswered questions, we cannot say that Iran is pursuing a nuclear weapons program." Interview with Amano, Der Spiegel, January 11, 2011, http://www.spiegel.de/international/world/0,1518,738634,00.html.
} 
1980s, when they cited the need for such weapons in light of Iran's concerns about perceived threats from Iraq and Israel, ${ }^{11}$ and likely reinforced by the contrasting examples of a nonnuclear Iraq (invaded), a denuclearized Libya (also invaded), and a nuclear North Korea (not invaded). A nuclear weapon would serve other likely regime interests as well, by strengthening Iran's would-be hegemonic military and political position in the Gulf region and admitting it to the exclusive global club of nuclear powers. The regime certainly has other interests, and its primary interest of regime survival depends not only on deterrence of external threats but also on economic prosperity and domestic stability, among other things.

We assume that a major U.S. aim is to prevent Iran from acquiring such a nuclear weapons capability. This was the U.S. objective under President George W. Bush and has remained so under President Obama. U.S. officials frequently and explicitly describe the nature of the Iranian threat to U.S. national security. For example, in testimony to the House Committee on Foreign Affairs, Deputy Secretary of State William Burns stated the following:

A nuclear-armed Iran would severely threaten the security and stability of a part of the world crucial to our interests and to the health of the global economy. It would seriously undermine the credibility of the United Nations and other international institutions, and seriously weaken the nuclear nonproliferation regime at precisely the moment when we are seeking to strengthen it. These risks are only reinforced by the wider actions of the Iranian leadership, particularly its longstanding support for violent terrorist groups like Hizballah and Hamas; its opposition to Middle East peace; its

\footnotetext{
11 For examples, see the Nuclear Threat Initiative's chronology of Iran's nuclear program,
} http://www.nti.org/e research/profiles/Iran/Nuclear/chronology.html. 
repugnant rhetoric about Israel, the Holocaust, 9/11, and so much else; and its brutal repression of its own citizens. ${ }^{12}$

Omitted from this statement is the damage that Iran's successful development of a nuclear weapons capability would have on U.S. influence and credibility in the Middle East and beyond. Given Washington's long-standing role as an external guarantor of stability in the region and its repeated presidential commitment to prevent Iran's nuclearization, failure in its aims would inevitably damage U.S. standing.

\section{U.S. AND IRANIAN PERCEPTIONS OF THEIR NO-DEAL OPTIONS}

Beyond enumerating potential deals and each side's interests, the framework calls for an assessment of each side's perception of what would happen if no deal were reached (its "no-deal option"). Relative to an interest assessment, the United States' and Iran's perceived no-deal options are more difficult to judge, as they require some speculation about how each side assesses what would actually transpire absent a negotiated agreement.

The United States' no-deal option — that is, its policy path should a negotiated agreement with Iran fail to be reached — has been a matter of significant controversy among analysts and policymakers. Absent an agreement limiting or eliminating Iran's nuclear program and without a change in the current U.S. approach, the likely outcome over time appears to be at least an Iranian nuclear weapons capability. If this transpires, the United States will need to choose between seeking to "contain" Iran or engaging in a military attack to destroy Iranian nuclear capabilities, assuming that passive U.S. acquiescence is off the table. Containing a nuclear-capable Iran will

12 William J. Burns, "Implementing Tougher Sanctions on Iran: A Progress Report," statement before the House Foreign Affairs Committee, Washington, D.C., December 1, 2010, http://www.state.gov/p/us/rm/2010/152222.htm. 
presumably be significantly more difficult than containing a nonnuclear Iran, which itself has proven a formidable challenge. At the same time, the United States — from a position of weakened influence and credibility — would need to maintain an international coalition in support of sanctions, when many countries may have a greater interest in accepting and accommodating Tehran's new nuclear status and resuming full economic and political relations. Over the longer term, the emergence of a nuclear-capable Iran may well spur other Middle Eastern powers to seek nuclear weapons capabilities of their own, presenting the United States with a new and challenging outburst of nuclear proliferation.

The other alternative to a negotiated agreement — an attack on Iran — is also not without downsides. Analysts and policymakers fear that a military attack would entail significant riskoperationally, economically, and in terms of likely retaliation-with uncertain efficacy. It is possible that keeping an Iranian nuclear weapons capability at bay would necessitate not just one but multiple attacks over the course of several years. Furthermore, an attack could prompt Iran's withdrawal from the Nonproliferation Treaty, the loss of the existing limited IAEA access in Iran, and a significant reduction in international support for sanctions. Top U.S. officials, including Secretary of Defense Leon Panetta, former Secretary of Defense Robert Gates, and former Chairman of the Joint Chiefs of Staff Adm. Michael Mullen, frequently warn about the downsides of military action against Iran, though noting that the possibility remains "on the table." 13 They similarly inveigh against Israeli military action. ${ }^{14}$

\footnotetext{
${ }^{13}$ See, for example, Adm. Mike Mullen, "Columbia University Press Avail," http://www.jcs.mil/speech.aspx?ID=1364.

14 See for example Paul Richter, “Gates Warns Against Israeli Strike on Iran's Nuclear Facilities," Los Angeles Times, April 16, 2009.
} 
It should come as little surprise that neither alternative to a negotiated agreement with Iran appears especially palatable — if it were, the United States under both Presidents Bush and Obama would not have expended so much time and effort on the negotiations themselves. Yet a choice must be made, and both Bush and Obama have clearly stated their preference for the "military option" to containment. In a March 2012 speech to a conference held by the American Israel Public Affairs Committee (AIPAC), President Obama stated, "When it comes to preventing Iran from obtaining a nuclear weapon, I will take no options off the table, and I mean what I say. That includes all elements of American power: a political effort aimed at isolating Iran, a diplomatic effort to sustain our coalition and ensure that the Iranian program is monitored, an economic effort that imposes crippling sanctions and, yes, a military effort to be prepared for any contingency." He further declared, "I do not have a policy of containment; I have a policy to prevent Iran from obtaining a nuclear weapon. And as I have made clear time and again during the course of my presidency, I will not hesitate to use force when it is necessary to defend the United States and its interests." 15 Whether this also implies a firm commitment to prevent Iran from developing a nuclear weapons capability, short of building a nuclear weapon, is unclear.

One of the great frustrations of U.S. policymakers and their counterparts in P5+1 countries is that, despite this avowed willingness to resort to military action and good-faith efforts to negotiate as an alternative to conflict, P5+1 negotiators have judged that Iranian proposals have not appeared to be seriously aimed at reaching compromise, at least through the Moscow talks in June 2012. This suggests that the Iranian regime views its own no-deal option favorably - as superior, at least, to the offers made thus far in the P $5+1$ talks. Indeed, all signs suggest that the Iranian Washington, D.C., March 4, 2012, http://www.politico.com/news/stories/0312/73588.html. 
regime likely sees its no-deal option as, in the absence of a negotiated agreement, an obstructed but still feasible path over time to a nuclear weapons capability.

This observation raises the question of why, if U.S. policymakers view military conflict as the most likely alternative to a negotiated agreement, the Iranian regime either does not see that eventuality as likely or does not worry overmuch about the consequences of such an outcome. The first explanation is provided above - U.S. officials, despite President Obama's insistence that the military option remains "on the table," often publicly deflate the notion that the United States will resort to force, and talk up the downsides of such a course of action to, some would say, the point of exaggeration. ${ }^{16}$ Perhaps more important - if one believes that actions speak louder than words over much of the last several years, the United States has made relatively little overt show of laying the groundwork, militarily or diplomatically, for a military offensive against Iranian nuclear facilities. Instead it appears to be signaling the construction of a regional containment regime consisting of missile defenses and other such defensive measures. This appeared to be changing in autumn 2012 as a series of visible military moves, especially joint minesweeping exercises in the region among some twenty-five countries, appear tailored to influence Iran's perceptions. ${ }^{17}$

The Israelis themselves have sent mixed messages regarding an attack on Iran, which could rapidly lead to U.S. involvement. Although Prime Minister Benjamin Netanyahu and Defense Minister Ehud Barak have warned of the possibility of an Israeli attack, they have done so for many years, which likely reduces the credibility of such warnings. In addition, other current and former

\footnotetext{
${ }^{16}$ For a discussion of this phenomenon, see Michael Eisenstadt and Michael Knights, "Beyond Worst-Case Analysis: Iran's Likely Responses to an Israeli Preventive Strike,” Police Notes, No. 11 (Washington, D.C.: Washington Institute for Near East Policy, June 2012).

17 See, for example, David E. Sanger and Eric Schmitt, "To Calm Israelis, U.S. Offers Ways to Restrain Iran," New York Times, September 3, 2012.
} 
Israeli officials, as well as Israeli President Shimon Peres, have warned in stark terms against an Israeli attack on Iran-with regard to its limited longer-term effectiveness, likely retaliation by Iran and its proxies, and cost in relations with the United States-projecting the sense that the matter is far from decided in Israel. ${ }^{18}$ In any event, it may be assumed that the Iranian regime - if it values survival above all else — worries less about an Israeli strike, which would likely be limited by Israeli capabilities to hit a narrow target set, than it does about a U.S. attack, which could have regime change as its object or effect.

Thus, in the absence of a negotiated agreement, the Iranian regime may foresee few insuperable impediments in the path toward a full nuclear weapons capability, though the timing of that trajectory will certainly be affected by actions of outside players. Consecutive rounds of sanctions have had a significant impact on the Iranian economy, but not apparently on the regime's nuclear ambitions. Nor do US policymakers appear to harbor hope that this will change; asked in June 2010 about the effects of greatly enhanced U.S. and Security Council sanctions, then-Director of Central Intelligence Leon Panetta responded, "Will it deter them from their ambitions with regards to nuclear capability? Probably not."19 Iran may also question the resilience of the current sanctions regime, given the likely increase in oil demand when global macroeconomic conditions improve, as well as historical cases such as the gradual degradation of sanctions against Iraq in the 1990s or the international community's speedy accommodation of Pakistan's nuclear status that same decade.

${ }^{18}$ See, for example, Shai Feldman, "The Israeli Debate on Attacking Iran is Over," Foreign Policy, August 20, 2012, http://mideast.foreignpolicy.com/posts/2012/08/20/the israeli debate on attacking iran is over, or, highlighting the dissent of former Mossad chief, Meir Dagan, see David Remnick "The Vegetarian," The New Yorker, September 3, 2012.

19 Jake Tapper interview with CIA Director Leon Panetta, ABC News, "This Week," Sunday, June 27, 2010, http://abcnews.go.com/ThisWeek/week-transcript-panetta/story?id=11025299\&page=1. 
Mostly implicit in the foregoing discussion is the critical and asymmetric role of the passage of time on each side's no-deal options. The U.S. interest in preventing a nuclear Iran is heightened by the widely held judgment that the time remaining before which Iran could produce nuclear weapons, if it chose to do so, is relatively short. This reflects the U.S. intelligence community's judgment that "Iran is technically capable of producing enough highly-enriched uranium for a weapon in the next few years [as of early 2010], if it chooses to do so."20 Western intelligence officials have suggested that their efforts have delayed Iranian nuclear progress, but they have not significantly changed the timetable for Iran to achieve nuclear weapons status. According to British press reports, British intelligence (MI6) Chief Sir John Sawers claimed that Western efforts had prevented Iran from obtaining a nuclear weapon by 2008, but that it would nevertheless achieve that goal by 2014 absent U.S. or Israeli military action. ${ }^{21}$ Simply put, therefore, as time passes without an effective nuclear agreement, centrifuges spin, Iran's nuclear program is buried in ever harder and deeper locations, Iran's no-deal option improves and that of the United States declines. ${ }^{22}$

Putting these elements-potential nuclear deals, each side's interests, and perceived nodeal options - together in stark form, we conclude that the implications for productive negotiations under circumstances as this writing remain negative. If the Iranian regime places an extremely high value on developing a military nuclear capability and sees its no-deal option as eventually acquiring such a capability, despite U.S. declaratory policy against such an outcome, while the U.S. demands Iranian agreement on limiting its nuclear options, "or else," it would not appear that a

\footnotetext{
${ }^{20}$ Blair, U.S. Intelligence Community Annual Threat Assessment.

${ }^{21}$ Quoted in Christopher Hope, "MI6 Chief Sir John Sawers: 'We Foiled Iranian Nuclear Weapons Bid,"' Daily Telegraph, July 12, 2012, http://www.telegraph.co.uk/news/uknews/terrorism-in-the-uk/9396360/MI6chief-Sir-John-Sawers-We-foiled-Iranian-nuclear-weapons-bid.html.

22 Absent a deal, only cost-imposing measures that escalate rapidly enough could reverse this conclusion.
} 
ZOPA exists in negotiations. If this is correct, then successful negotiations will require more than wise process or technique; further concrete actions to create and widen a ZOPA will be necessary in addition to tough diplomacy.

\section{A Simple Analytical Framework: Graphical Development}

With these interests, no-deal options, and possible agreements in mind, we can begin to represent the analytical framework in graphical form. As before and with similar caveats to those outlined above, the framework begins with a purposefully basic setup — two monolithic parties facing a range of simplified nuclear-related deals and the no-deal options that currently prevail — and moves to incorporate the effects of sanctions, military threats of varying credibility, and other costimposing moves as well as the effects of incentives and inducements embodied in potential agreements. As an output, the framework illustrates the existence and location of the zone of possible agreement, and the range of deals that fall within that ZOPA, given a particular combination of costs, incentives, and no-deal options. Going forward, we can manipulate the framework to represent different combinations of no-deal options, include other potential deals, and consider how other policy decisions affect the ZOPA and range of feasible agreements.

The graphical representation of the framework is built around two axes; the horizontal axis represents value for the United States, and the vertical axis represents value for the Iranian regime (see figure 1). Thus, moving "up" (or "north") means increasing value for the Iranian regime (where higher "value" is associated with meeting Iranian regime interests more fully), and moving "right" (or "east") means doing the same for the United States. Running between these axes is a downward-sloping "frontier" representing a stylized range of possible outcomes for Iran's nuclear program. Although a fuller set of creative options might be envisioned, and are later discussed, we 
initially focus on outcomes or deals limited to nuclear issues of central concern to policymakers. Those options in the upper left are best for Iran, and those in the lower right are best for the United States. The absolute locations of the deals are merely illustrative, but their order is meaningful. ${ }^{23}$ This representation of the spectrum of possible nuclear deals is purposefully simplistic. In reality, the spacing between the deals might be irregular, and each party might perceive that spacing differently. Furthermore, it is possible that, from one or the other party's perspective, there is no practical difference between two deals. For example, the consequences for the United States of an Iranian nuclear weapons capability may be roughly the same as those of Iran possessing an actual nuclear weapon. Different outcome evaluations than those shown would simply require a redrawn "frontier" diagonal.24

${ }^{23}$ Were we to move further southeast on the diagonal line of possible agreements, we might include regime change as an outcome; similarly, moving further northwest might entail a large Iranian nuclear arsenal plus ballistic missile delivery capability. Moreover, the potential deals displayed on the diagonal line are limited to nuclear issues; other, more complex deals, perhaps with other linkages-such as economic, political, or security-are discussed subsequently in the section on incentives.

${ }^{24}$ Deals that simultaneously improve each side's outcomes would cause the frontier to bow outward or become convex. 
Figure 1. Basic Graphical Representation of the U.S.-Iranian Nuclear Negotiations

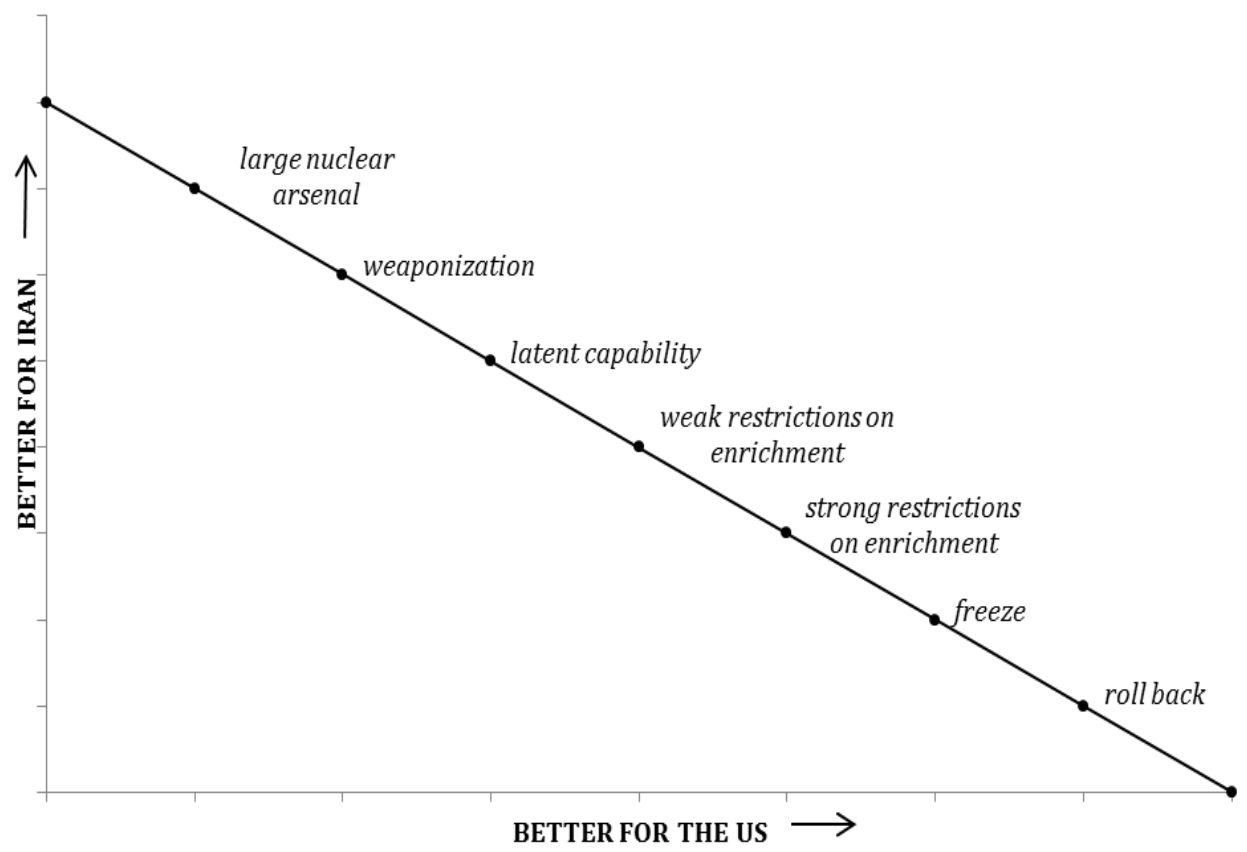

In figure 2, we introduce a series of lines perpendicular to the axes. Line $A B$, which crosses the deal frontier at "freeze," represents the United States' stated position that Iran must, at a minimum, freeze its uranium enrichment at current levels. ${ }^{25}$ For purposes of illustrating the framework, we have indicated line $\mathrm{CD}$, which crosses the frontier at or near "weaponization," as the likely (eventual) outcome given current U.S. policy—under the presumption of tightening sanctions

25 The relevant UN Security Council resolutions, including UNSC Resolution 1929, actually call for Iran to suspend all uranium enrichment and reprocessing activities (which corresponds to "rollback" on the indicated frontier). We judge, however, that the United States' willingness to consider swapping Iran's indigenously produced low-enriched uranium for highly enriched uranium in October 2009 and its reported request in the summer 2012 negotiating rounds that Iran freeze only its $19.75 \%$ enrichment activities rather than freeze all enrichment work indicate an implicit acceptance by the Obama Administration of some low level of uranium enrichment. 
but no military action. ${ }^{26}$ Presumably, somewhere between these two lines lies the true U.S. minimum (or "red line"). This red line represents the "most nuclear" Iran the Obama administration could accept—and hence its minimum conditions for an acceptable deal—before turning to more costly alternatives to negotiation (including military action).

While we illustrate the graphical framework under the mainstream policy assumptions described above, very different views can be readily accommodated. For example, Kenneth Waltz prominently claims that an Iranian bomb would lead to greater Middle East stability, not less. ${ }^{27}$ His argument implies that the consequences of no-deal for the United States would be positive; thus, the location of $\mathrm{CD}$ would be significantly rightward than its placement under more conventional assumptions.

Line EF represents, from the Iranian regime's perspective, the minimum acceptable outcome of Iran's nuclear program conditional on a no-deal outcome that leaves Tehran undeterred; as such, the regime's placement represents its red line, or effectively the minimum outcome to which it would agree. The line's placement reflects the view, discussed earlier, that the Iranian regime deems at least a nuclear weapons capability as vital to its interests and, on current no-deal policy trajectories, will sooner or later achieve this goal. Different factions within Iran may prefer less or more aggressive outcomes, and the internal struggle among those factions could cause EF to move up or down accordingly.

${ }^{26}$ The placement of CD is in line with Leon Panetta's judgment, expressed in note 16 of this article, Of course, those who judge that the most likely outcome of current U.S. policy would be more (or less) favorable to U.S. interests would shift the location of line $\mathrm{CD}$ to the right (or left).

${ }^{27}$ Kenneth Waltz, "Why Iran Should Get the Bomb," Foreign Affairs, Vol. 91, No. 4, (July/August 2012), pp. 2-5. 
Figure 2. Selected Negotiating Positions and Likely No-deal Outcomes

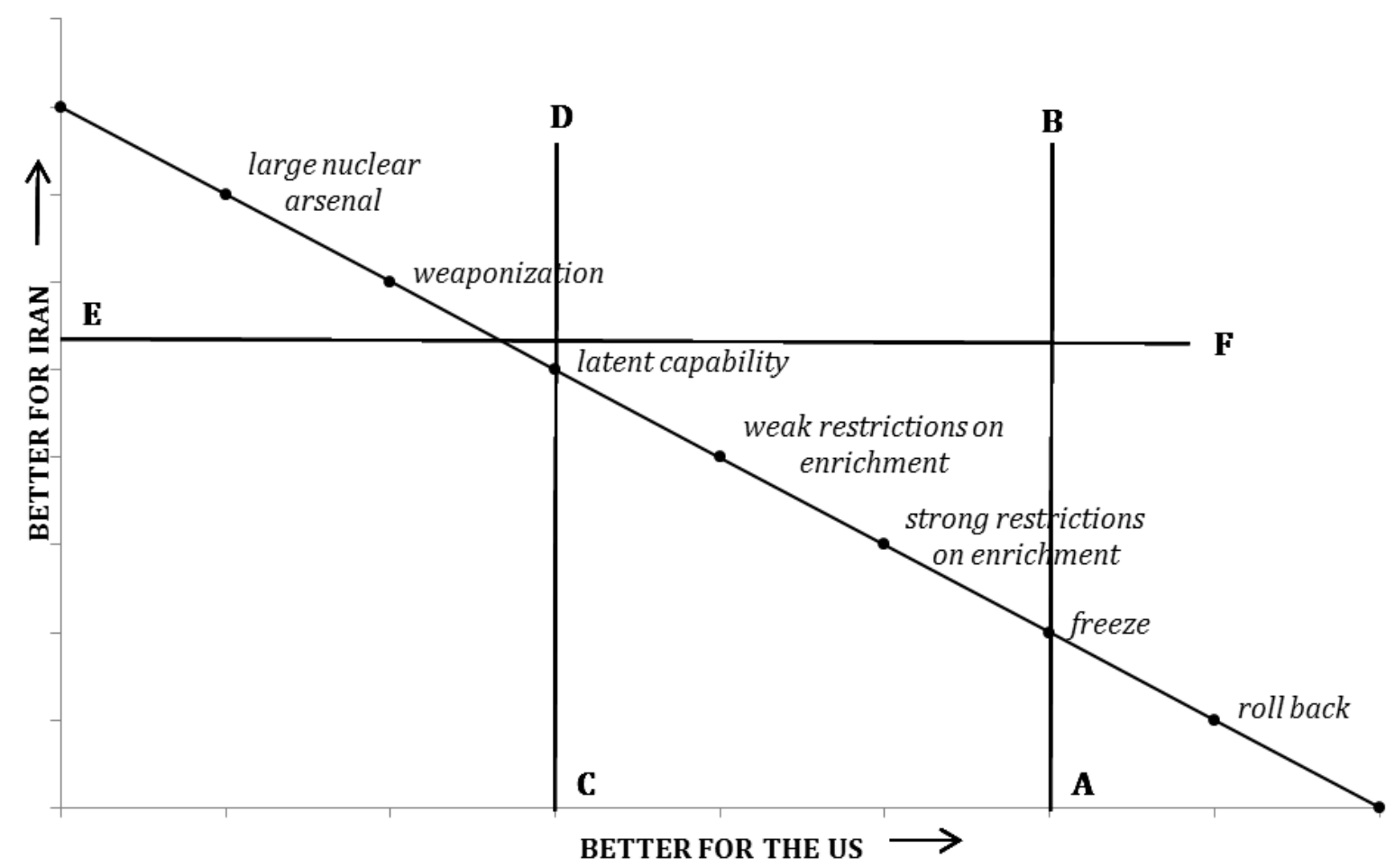

With these elements in place under the specified assumptions, we can determine whether or not a ZOPA exists, and if so, what range of deals falls within it. In this "base case," meant to illustrate the present state of the negotiations (as of this writing), whether a ZOPA exists depends critically on the location of U.S. and Iranian red lines. The portion of the deal frontier, if any, that is the diagonal line segment above EF (or an alternative horizontal line representing the Iranian red line, depending on one's assessment of Iran's no-deal options) and to the right of the U.S. red line (whether $\mathrm{AB}, \mathrm{CD}$, or a line in between) - represents the ZOPA; that is, all of the deals on the portion of the diagonal frontier bounded by a line representing the US minimum and EF would be acceptable to both parties relative to their no-deal options. Which of these agreements the two 
parties might reach, if any, depends on the previously discussed "at the table" dimensions of the negotiation — deal design and negotiating tactics. ${ }^{28}$ With this in mind, it is clear that if the declared U.S. position of $A B$ is the true U.S. minimum, then no ZOPA exists, as the deal frontier would not pass through the portion of the graph above EF and to the right of AB. Given that the Obama administration's true red line is likely to lie somewhere between $\mathrm{AB}$ and $\mathrm{CD}$, it is likely that no ZOPA currently exists (again, presuming that EF represents the Iranian minimum conditional on the regime's perception of the actual consequences of no deal).

In most negotiations, neither party has perfect information regarding the other's true red lines given its no-deal options, and therefore must guess at these minimum deal conditions and thus the existence and size of the ZOPA, which is that region of the graph that is simultaneously better than each side's no-deal option (northeast of the intersection of CD and EF). This problem is particularly acute in the Iran nuclear negotiations, given the paucity of official U.S. contacts since the 1979 Islamic Revolution in Iran, meaning that the parties' estimates of each other's red lines are largely based on indirectly informed perceptions. In addition, each party's red line is not only a matter of executive fiat, but is also the product of side negotiations with internal parties and external allies. Until such side negotiations are concluded, negotiators can only estimate their own red lines as well. ${ }^{29}$ As a result of this process of estimating one's own and the other party's red

28 The fact that an agreement is better than actual no-deal options need not imply its acknowledgment or acceptance by both parties. Should the parties involve new issues and invent any additional, creative options that fall northeast of the intersection of CD and EF, such options would also lie within the ZOPA. Such options are considered shortly.

${ }^{29}$ Simplistically, even after abstracting from the problem of alliance negotiations, the U.S. red line should be located at the point representing the most-nuclear Iran that the United States is willing to accept. Properly determining such a red line, from a prescriptive-not descriptive--standpoint is analytically elaborate, in both principle and practice. Think of the U.S. red line as the all-things-considered, maximally acceptable nuclear Iran, in the event that negotiations fail and the United States takes corresponding actions. This outcome should set the no-deal value, or lower limit of acceptability, for any negotiated agreement with Iran. 
lines, each party will have its own perception of the existence and location of a ZOPA. Especially in a relationship characterized by misunderstanding and poor communication, these two pictures may bear little resemblance to each other. Common bargaining tactics may exacerbate this problem further, with potentially dire consequences. ${ }^{30}$

\section{REPRESENTING THE EFFECTS OF SANCTIONS AND INCENTIVES}

The two tools employed most frequently by the United States and its allies in an effort to change the Iranian regime's strategic calculus are sanctions (more generally, cost-imposing measures of any kind) and incentives (more generally, deal provisions intended to be of value to Iran's regime or value-enhancing measures of any kind). "Costs" in this formulation can include both punitive measures not directly related to Iran's nuclear program as well as actions that make Iranian

To determine where it should lie, both the expected costs and expected deterrence benefits of increased unilateral (nonnegotiated) actions must be considered. In other words, U.S. policymakers should see how bad a given outcome really is and ask what costs they should be willing to incur to avoid that outcome in order to ensure a better outcome (with "better" here judged net of the associated costs of the deterrence actions). More generally, as long as the expected incremental costs of deterrence (including the cost of any benefits separately conferred for this purpose) are less than the expected incremental value of increased deterrence conditional on those costs, the United States should be willing to incur such further costs. The resulting outcome value should represent the U.S. red line, or the best no-deal option; with this in mind, the United States should seek a negotiated outcome superior to the optimal nonnegotiated options.

${ }^{30}$ For a party that desires a negotiated agreement, establishing correct perceptions can raise a thorny tactical dilemma. Imagine that you walk into a car dealership prepared to spend $\$ 50,000$, but convincingly assert that you will not spend a penny over $\$ 35,000$. The dealer may not even bother negotiating with you, rather than simply offering you a $\$ 10,000$ break on the $\$ 50,000$ car that you wanted (a deal that he was actually prepared to give you if push came to shove). In this case, you would have been well advised to soften your position to get talks started. In any negotiation, if the other party views your position as harder line than it truly is, there may be utility in partially correcting that impression to convince the other party to give negotiations a serious effort. In doing so, however, you may benefit the other party in any actual negotiation by allowing them to press for a deal as close to your red line-and as far from their own-as possible, and raise opposition among internal factions. The reverse is also possible-if, for example, Iran believes the United States will not countenance a war, but the United States in fact considers a military attack to be its best no-deal option, the regime, in holding out for a better deal, may in fact bring an attack upon itself. 
military nuclear potential less likely, further delayed, and otherwise degraded. Both of these tools, and their effects on the ZOPA, can be illustrated using this framework. ${ }^{31}$

If, for example, the United States credibly imposes actual and expected no-deal costs of magnitude EH on Iran, the Iranian regime's new minimum would be represented by the line HJ (see figure 3). The new ZOPA would be the portion of the diagonal line above HJ and to the right of the U.S. red line (on the assumption that a deal would lead to the removal of the actual sanctions/costs or credible threat thereof). If the U.S. red line were anywhere to the left of the point at which HJ intersects the deal frontier, this cost-imposing move will have created or expanded a ZOPA and therefore made a broader range of negotiated agreements possible. ${ }^{32}$

\footnotetext{
${ }^{31}$ For simplicity, we treat the effects of costs as if they were actually imposed. However, genuinely credible, specific threats to do so can easily be incorporated in the framework as expected costs. Similarly, we treat effects of incentives as if they were actually conferred in a deal, though genuinely credible promises to do so can easily be incorporated into the framework as expected benefits.

${ }^{32}$ Note that, though for clarity we have not indicated it in the graph, measures that obstruct, delay, or degrade Iran's military nuclear capability simultaneously improve the U.S. no-deal option in the event that negotiations drag on or fail outright.
} 
Figure 3: The Effect of Sanctions of Magnitude EH on Expanding the ZOPA

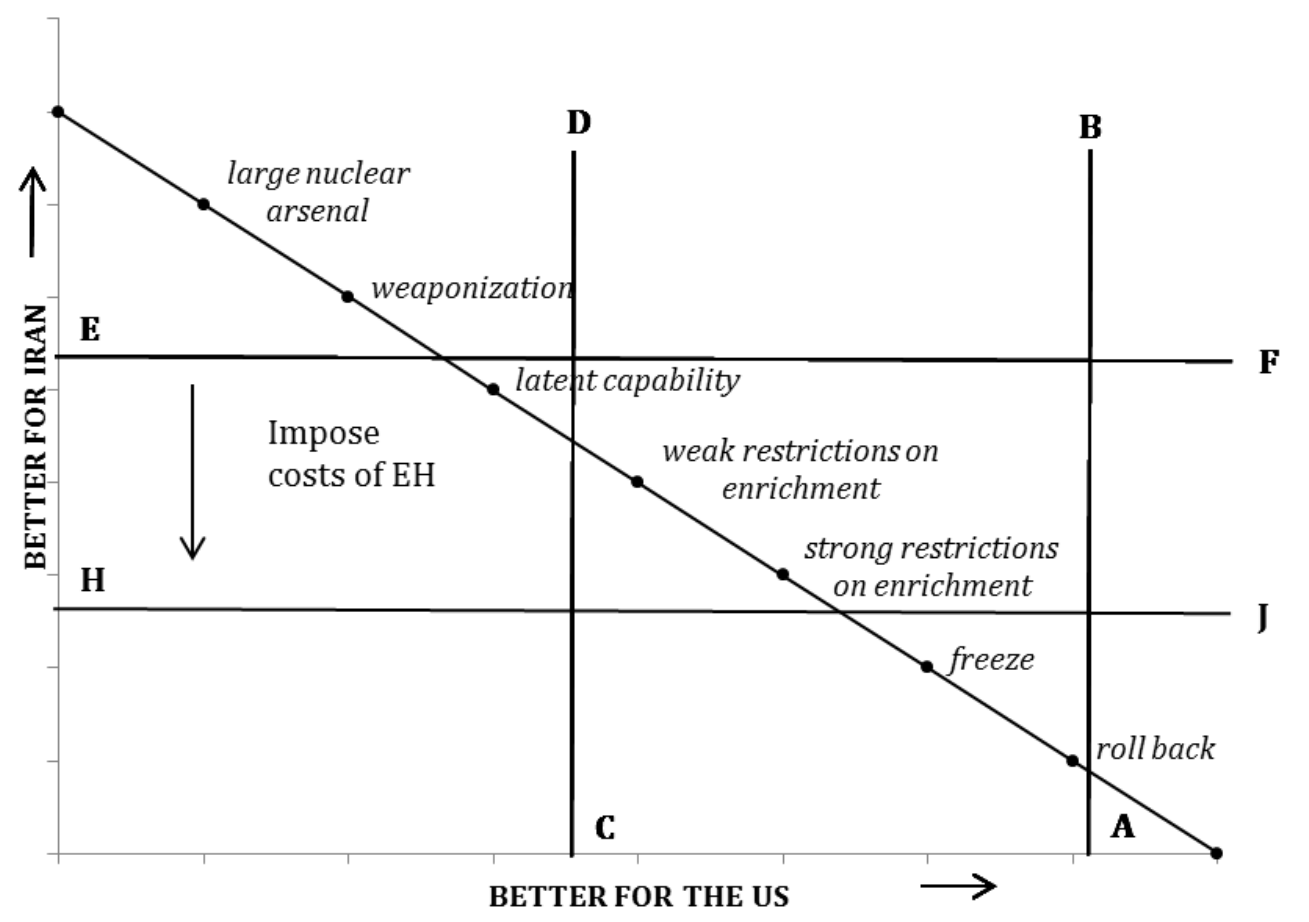

We again note that very different views from the mainstream assumptions we have been illustrating can easily be accommodated by our graphical framework. For example, some analysts argue that sanctions merely provide a beleaguered Iranian leadership with a classic "rally around the flag response" that has the "opposite effect" from that intended. ${ }^{33}$ Under such an assumption, the position of EH would be shifted up, or northward of EF, by the magnitude of the positive effect.

Similarly, the United States could in the context of an agreement offer incentives that add to the value of the agreement for Iran. In the framework, this would be represented as an upward shift of the deal frontier and, depending on the magnitude of the incentives, could extend both north

${ }^{33}$ See, for example, George Lopez, "Sanctioning Iran Further Won't Work," Bulletin of the Atomic Scientists, January 6, 2010, http://www.thebulletin.org/web-edition/op-eds/sanctioning-iran-further-wont-work. 
and east of the diagonal as indicated by the shaded rectangle (see figure 4). ${ }^{34}$ Such incentives would increase the value to Iran of any negotiated agreement, while not changing the value of the deal to the United States. The position of EF does not change, but the ZOPA would become the shaded region above EF and to the right of the U.S. red line, whether that is $C D, A B$, or a line between these two. Even though the two parties' minima do not change, the shift in the deal frontier has positive implications for the existence and location of the ZOPA. If the U.S. red line were anywhere to the left of the point at which EF intersects the new deal frontier, the credible offer of meaningful incentives will have created or expanded a ZOPA and therefore made a broader range of negotiated agreements possible. It is worth noting that none of the deals that are newly located in the ZOPA in this scenario are "worse" for the United States than what it would have been prepared to accept before offering the incentives. ${ }^{35}$

\footnotetext{
${ }^{34}$ With incentives, agreement would encompass more than the purely nuclear-related deals considered up to this point, and would better be characterized as packages of nuclear provisions and other issues.

35 This would be true unless the incentives were costly to the United States to offer, in which case the deal frontier would shift to the left by the magnitude of the cost.
} 
Figure 4. The Effect of Incentives on the ZOPA

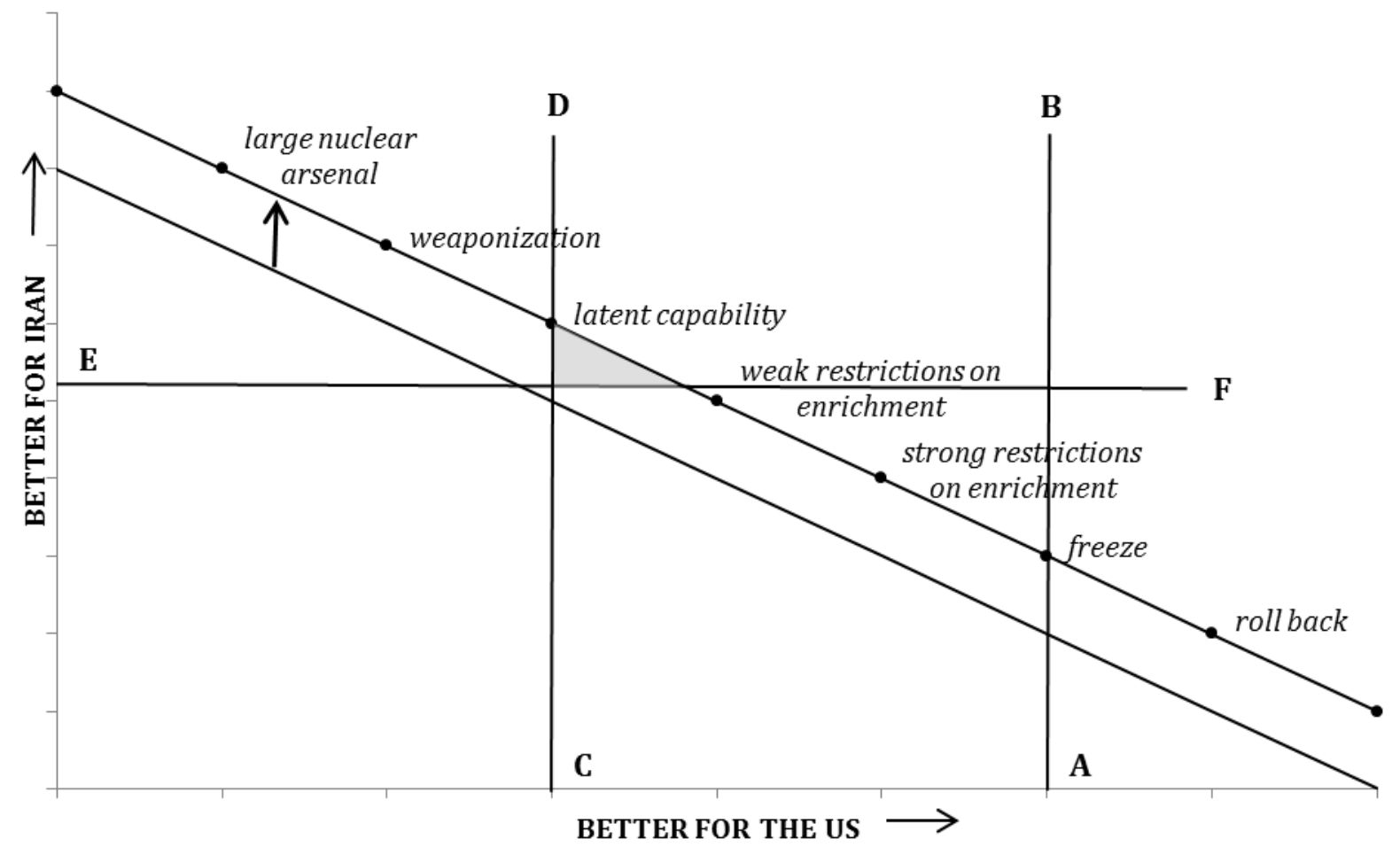

This effect can also operate in reverse; that is, if the United States provides Iran with disincentives, the deal frontier shifts downward, constricting or eliminating the ZOPA (see figure 5). An example of such a disincentive would be the precondition that Iran suspend uranium enrichment during any negotiations; this represents a cost for Iran, but unlike the costs discussed above, it is associated not with a refusal to negotiate but with an agreement to negotiate. Thus it operates not like a cost (shifting EF downward), but as a reverse incentive, or disincentive. This assumes, it should be noted, that the precondition is reversible - that is, if no deal is reached, the condition ceases to hold, and if a deal is reached, the condition is not necessarily a part of it. If the precondition is irreversible, it would behave as a cost or as a modification of the deal itself and thus would be represented by movement along the frontier, depending on the precondition in question. 
This is not to say that preconditions should or should not be used; rather that, when they are employed, their impact on the ZOPA should be kept in mind.

Figure 5. The Effect of Preconditions on the ZOPA

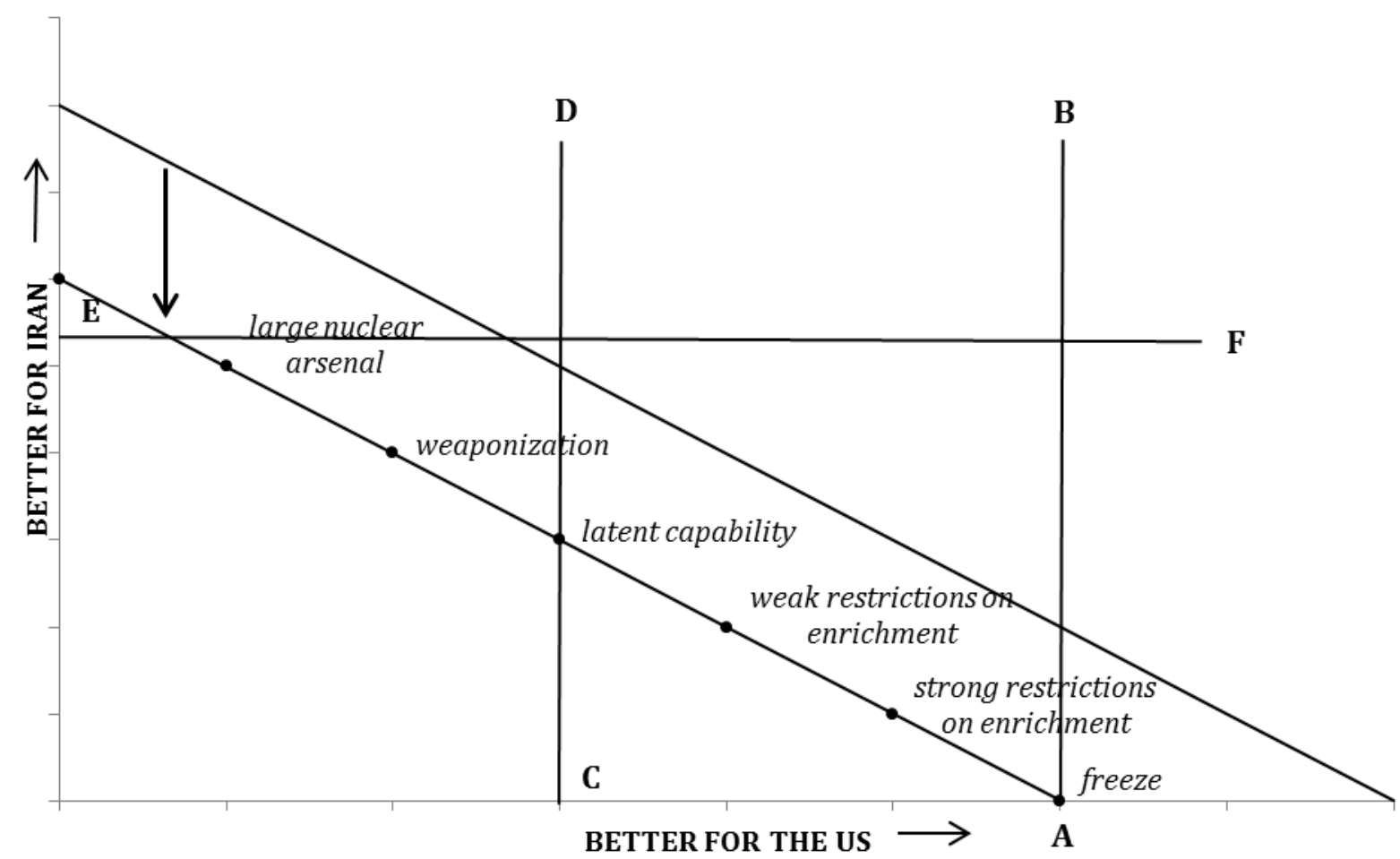

In the case of the Iran nuclear negotiations, sanctions and incentives need not be used separately, but could be paired to amplify the effect on the Iranian regime's calculations. This possibility can be represented in the framework by combining the imposition of costs of magnitude EH (creating a new Iranian minimum of $\mathrm{HJ}$ ) with offering incentives that shift the deal frontier upward (see figure 6) and may extend it further "northeast." The combined effect of these two is a new ZOPA above HJ and to the right of the U.S. red line. The combined effect of these policies is to further expand the ZOPA — in this (illustrative) case, creating a ZOPA even if the true U.S. red line is its declared position of AB. Previously infeasible agreements are moved into the ZOPA, providing 
greater leeway for U.S. and Iranian negotiators and therefore increasing the chances of a negotiated agreement, given the right negotiating process and tactics.

Figure 6. The Effects on the ZOPA of Combining Sanctions and Incentives

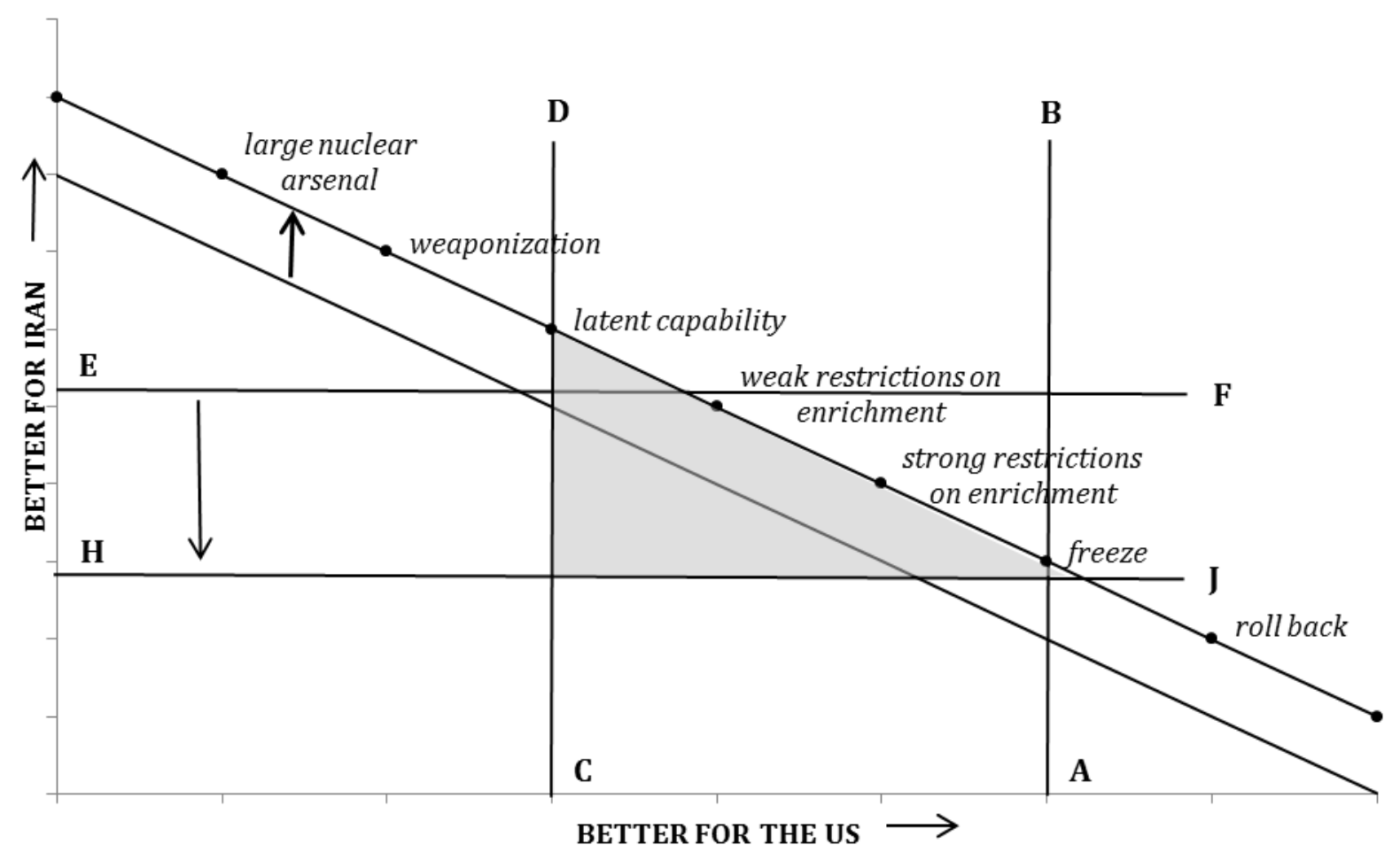

\section{Costs and Incentives That Can Affect the ZOPA}

The challenge that has bedeviled international diplomacy over Iran's nuclear program is identifying policy levers that can bring Iran to the negotiating table and influence its decisions. Too often, costs and incentives are thought of simplistically as "punishments" and "rewards," and are wielded haphazardly and independently; instead, they should be used in concert as part of a coordinated strategy to open a ZOPA and provide diplomacy with a prospect for success. 
While the term "costs" is frequently equated with sanctions, this is too narrow. We use "costs" for any measures that meaningfully worsen the hard-line regime's alternatives to reaching agreement on its nuclear program. While costs certainly include sanctions, the term also includes any measures that delay, degrade, or stop Iran's efforts at military uses of nuclear power; actions that impose negative consequences not directly related to its nuclear program (e.g., travel bans on top Iranian officials); as well as the level of expectation that no-deal will lead to military action. This last clause merits elaboration: it is not necessary for a cost to be actually imposed for it to worsen the Iranian regime's no deal option. If the regime has an ironclad level of certainty that such measures will be forthcoming absent a deal or if specified red lines are crossed-and this, of course, is a big "if" - the threatened cost analytically functions the same as an imposed cost. This leads to a broader discussion: to be effective, any cost or incentive must meet three criteria.

First, costs and incentives must enjoy credibility in the eyes of the other party. To this end, actions speak louder than words. For example, if the United States were to threaten Iran militarily while making no visible effort to prepare the ground politically or practically for such actions, the "military option" will lack credibility. It certainly does not help that, according to Graham Allison, the United States and its allies have allowed Iran to cross multiple red lines over eighteen years with few consequences. ${ }^{36}$ Likewise, it is undoubtedly instructive to Iran that the United States largely acquiesced to a North Korean nuclear weapons capability after having repeatedly declared such an eventuality "unacceptable." The regime may see certain sanctions, in particular, as less credible if it believes that the sanctions will begin to crumble as soon as Iran obtains nuclear weapons. Similarly, if U.S. negotiators offer to lift sanctions, but that action requires the cooperation

\footnotetext{
${ }^{36}$ Sanger and Schmitt, “To Calm Israelis, U.S. Offers Ways to Restrain Iran.”
} 
of a Congress that is opposed to the measure, the incentive would not be credible. Credibility is also reinforced (or undermined) by actions and policies in other arenas.

Second, costs and incentives must also be meaningful as regards the regime's actual interests - costs must threaten those interests and incentives must further them. In other words, they must be in the right "currency." It is easy to wrongly project one's view of the other's interests; for example, although better relations with the United States or membership in the World Trade Organization (WTO) may seem like obvious "pluses" to Iran's hard-line regime, it may instead see these as undesirable, even as threats if regime survival depends on isolation and stoking domestic Iranian paranoia about "external enemies." Getting the "currency" right, and thus effectively employing costs and incentives, requires an accurate understanding of how the regime perceives its interests.

Third, beyond merely harming Iranian interests, costs must be of sufficient magnitude relative to the regime's perception of the value of its no-deal option to sufficiently shift the Iranian red line downward (e.g., from $E F$ to $H J$ in figure 3), and thus, to have an appreciable effect on the potential ZOPA. Benefits must be of analogous magnitude to induce an upward and rightward ("northeast") shift in the ZOPA. The scant examples of previous strategic shifts by Iran suggest that the regime is prepared to endure heavy costs in pursuit of what it sees as vital interests. One such shift occurred when Ayatollah Ruhollah Khomeini accepted a cease-fire to end the bloody, eightyear Iran-Iraq War — after insisting he would never do so — only after Iran's navy had been soundly beaten by the United States and an Iranian civilian airliner was mistakenly shot down by the USS Vincennes. Another may have occurred in 2003, when, spurred by the U.S. invasions of Afghanistan and Iraq and fears that Iran could be next, Iran apparently suspended its nuclear 
weaponization work and entered nuclear negotiations with the United Kingdom, France, and Germany. Of course, apart from moves that impose unrelated costs on Iran, actions that directly obstruct, delay, or otherwise degrade the military potential of Iran's nuclear program by definition shift its no-deal option downward.

In thinking about which costs and incentives to employ, the United States and its allies need to assess not only the effectiveness of the measures according to these three criteria, but also the cost to themselves of imposing the measures. Although for purposes of exposition when laying out the framework above, we assumed that costs and incentives could be used costlessly by the United States, this is not true in general. For example, the restrictions in place on Iran's oil exports have reportedly taken more than 1.2 million barrels per day or more oil off world markets, which presumably has resulted in higher oil prices than would otherwise prevail.

\section{Costs}

As noted above, when devising costs to impose on the Iranian regime for pursuing a nuclear weapons capability, it is critical to understand how the regime itself perceives its interests. For many years, the United States utilized broad sanctions in an effort to isolate Iran, including a ban on all imports from Iran in 1987 and a ban on almost all exports to and investment in Iran in 1995. Certain elements of the Iranian regime, however, may welcome such isolation from the United States. In part, this exemplifies the routine desire shared by autocratic regimes to regulate and restrict their citizens' interactions with the outside world. Yet as Iran expert Karim Sadjadpour has observed, ${ }^{37}$ under Supreme Leader Ali Khamenei, Iran has held independence and self-sufficiency as two core political values. Khamenei believes that previous Iranian rulers were weakened and

\footnotetext{
${ }^{37}$ Sadjadpour, Reading Khamenei.
} 
corrupted by reliance on foreign powers, and he is determined that his regime will rely on indigenous advances. As a result, it is unlikely that he views being cut off from the U.S. politically or economically in negative terms.

Since 2000, the U.S. approach to costs has changed, mostly focusing on measures more deliberately targeting the interests of the regime and the programs (nuclear, ballistic missile, terrorism sponsorship) of greatest international concern. Insofar as those measures enjoy greater multilateral support and threaten more directly the interests of the regime, they better meet the first two criteria mentioned above in being credible and meaningful. And, of course, far more severe sanctions have been imposed in 2012 on Iran's oil exports and transactions involving its central bank. These have led to substantial drops in Iran's oil exports (on which 70 percent of its budget depends) and a dramatic fall in the Iranian rial—and sharpens the question among analysts "Will Iran crack?"38 If one accepts the provisional conclusion, certainly as of the Moscow negotiations in June 2012, that a ZOPA has not yet become evident, it follows that the actual and prospective costs imposed on Iran to date have themselves been insufficient in magnitude relative to its no-deal option.

While the United States and its allies may eventually conclude that diplomatic efforts to open a ZOPA and reach a nuclear deal with Iran have failed and turn instead to no-deal options, they can be expected to continue seeking tighter sanctions to impose until such a conclusion is reached. Singly or in combination, such costs could be represented in the graphical framework by their effects on EF and, in some cases, on CD-in that they improve the outcome for the United

38 See, for example, Meghan L. O'Sullivan. "Will Iran Crack?" Los Angeles Times, July 6, 2012. http://articles.latimes.com/2012/jul/06/opinion/la-oe-0705-osullivan-sanctions-iran-20120706. 
States as long as no deal is reached, or if negotiations utterly fail (see figures 2 and 3). These costimposing measures can be placed into two broad categories based on their effects on the elements of the analytical framework described above.

The first category is "side costs." The analytic opposite of side payments, these are costs that reduce the "net value" to Iran of its no-deal option (an eventual nuclear weapons capability), but are otherwise substantively unrelated to the nuclear issue. Examples would include additional restrictions on global trade with Iran or sanctions on international firms that provide goods or services used by the Iranian regime in perpetrating human rights abuses. Such measures have their own merits and drawbacks, but they do not in themselves directly interfere with Iran's ability to achieve its nuclear aims. Nor do they improve the U.S. outcome in the event of no deal; analytically, they move EF down.

The second category comprises measures to delay/degrade/stop Iran's nuclear program. These are measures that directly or indirectly worsen Iran's nuclear no-deal option. By this, we mean actions that increase the difficulty or time required for Iran to achieve its military nuclear aims, that degrade the effectiveness of that program, or that completely block its success. We note that the effects of such measures on Iran's nuclear program may occur during negotiations-as long as no deal is reached-or if negotiations definitively fail. Importantly, such measures simultaneously improve the U.S. no-deal option and therefore may decrease the urgency-or, conceivably, the need at all-for the United States and its allies to reach a deal with Iran. (In this sense, such actions move line segment $C D$ to the right.) These measures can target the nuclear program itself - for example, by prohibiting the export to Iran of essential nuclear components or dual-use items - or support functions such as restrictions on shipping and finance. 
Coercive actions, such as military strikes, also fall into the second category of costs, but their qualitatively different character merits further, separate discussion. If credible, under the assumptions we have outlined, military threats worsen Iranian perceptions of the consequences of failure to reach a deal. (Actual use of force, to the extent it were effective in delaying/degrading the Iranian nuclear program, could directly improve the no-deal option of the United States, though presumably the scope for agreement at that point would be almost nil—or the kind of negotiations subsequent to such action would likely be qualitatively different from those preceding it.) Independent of the underlying benefits and drawbacks of the use of force, increasing the credibility and salience of the military option seems to be a major way to open up a ZOPA by worsening nodeal perceptions. Instances of Iran making strategic shifts — whether by signing a cease-fire at the end of the Iran-Iraq War or suspending weaponization work around 2003 — suggest that a credible military threat can potently influence the regime's calculus, which is unsurprising if regime survival is its primary interest and military action would threaten it. The realistic prospect of military action may also strengthen the U.S. coalition by motivating those allies with important commercial concerns (e.g., China) to cooperate more fully with sanctions and other measures in hopes of forestalling armed conflict that would be inimical to their interests.

Steps that appear to lay the groundwork for military action (e.g., regional exercises or prepositioning of military assets) are likely to enhance the credibility of coercive measures. On the other hand, purely defensive measures aimed at containing Iran, though perhaps prudent on their merits, may have the opposite effect of signaling international resignation to a nuclear-armed Iran. Thus, care should be taken in the way such defensive steps are implemented and publicly framed. 
As mentioned above, reinforcing the threat of military force should worsen Iran's no-deal option and increase the prospects for opening a ZOPA, though some analysts argue that the regime would welcome the "rally-round-the-flag" effect of military actions (in which case the intended coercive effects would be reversed). If, however, Iran perceives that military action is not an alternative to a negotiated outcome for the United States with respect to nuclear issues, but rather the United States really seeks regime change, the efficacy of the military threat on nuclear issues would be diminished. In this case, Iran would perceive the U.S. red line shifting sharply to the right, leading to a narrowing or elimination of the Iranian estimation of the ZOPA. ${ }^{39}$ If the regime is convinced that the nuclear talks are a proxy or cover for a policy of regime change, no deal will be possible. However, the threat of military action — absent a nuclear agreement — which could degrade the regime is not incompatible with negotiations, because it is a consequence of "no-deal" rather than the actual U.S. objective.

\section{INCENTIVES}

As with costs, designing credible, meaningful, and high-impact incentives requires a clear understanding of how the Iranian regime sees its interests. Similar to costs, incentives can be grouped into three broad categories.

The first category is removal of negatives. These incentives are essentially the reversal or removal of costs previously imposed or threatened. These could include the lifting of sanctions, security or nonbelligerency guarantees, and other such measures.

39 If the United States' primary interest were in regime change with the nuclear issues functioning only as a proxy for this deeper interest, then the U.S. red line would become more demanding (move to the right in figure 2, for example), ruling out otherwise acceptable nuclear outcomes. 
The second category is composed of side payments. These are incentives meant to increase the "net value" to Iran of a particular agreement that are otherwise unrelated to the nuclear issue except as a bargaining tactic. In addition, these incentives do not directly advance U.S. interests, and so add no value to the agreement from the U.S. perspective. These could include agricultural assistance, trade agreements, assistance with civil aviation, and other such measures.

The third category comprises joint gains, incentives that increase the value of a particular agreement to both Iran and the United States, and can thus be thought of as "win-win." These might include measures in the areas of counternarcotics, cooperation on Afghan security, and the like. As an accompaniment to a solid, verifiable nuclear deal, actions that increase Iran's oil output could offer joint gain in that available global oil supplies would increase, prices would fall, and Iranian government revenues would increase. To the extent, however, that the Iranian regime seems to view its relations with the United States in zero-sum terms, the opportunities for joint gains appear slim.

Devising incentives that are enticing to Iran and palatable to the United States has proven difficult. Although threatening the regime's interests with costs is generally an easy sell politically in the United States, Europe, and elsewhere, satisfying the regime's interests through incentives is more complicated. Helping the regime ensure its survival — for example, by forgoing support for dissidents or offering security or nonbelligerency guarantees — is morally problematic for the United States and its allies, and would encounter stiff opposition in those countries. 
As a result of this conundrum, the United States and its allies tend to offer incentives that suggest an unrealistic reading of the Iranian regime's interests. ${ }^{40}$ This is borne out by an example from recent years. The United States dropped its objection to Iran joining the WTO in 2005 after receiving criticism from the EU, Iran, and others; since that time, however, Iran has done little to pursue WTO membership, and in December 2010, the Iranian Parliament voted to further slow down the (nearly halted) process of WTO accession. ${ }^{41}$ If, as previously noted, the hard-line regime values political and economic independence and self-sufficiency, it is easy to see why it would find WTO membership, and similar measures such as full normalization of relations with the United States, problematic.

Correspondingly, the incentives that have already been offered by the United States and its allies - the suspension of sanctions, reassurances regarding Iran's territorial integrity, cooperation on civil nuclear energy, regional security, trade, and civil aviation, as well as assistance with agricultural, economic, and technological development — have thus far elicited scant interest from Iran. This suggests that the regime either does not value such inducements, at least relative to a nuclear path, or in its deep suspicion of Western aims, deems them not credible or of insufficient magnitude. The Iranian regime may suffer from a principal-agent problem as well, in that certain incentives may be beneficial to Iran as a nation, but the benefit to the Iranian regime or individual Iranian officials of accepting them is outweighed by the political cost of doing so. The perverse

\footnotetext{
${ }^{40}$ For an account of the most recent P5+1 offer made to Iran, see, for example, Jay Solomon and Farnaz Fassihi, "Iran Balks at Nuclear Offer, Calls for End to Sanctions," Wall Street Journal, May 23, 2012, http://online.wsj.com/article/SB10001424052702304707604577421760274208988.html. For Iran's response, see "Iran's Proposals to Six World Powers in Moscow Talks," Fars News, July 7, 2912, http://english.farsnews.com/newstext.php?nn=9103085486. For the previous incentives package offered to Iran by the P5+1, see "P5+1 Updated Incentives Package," press release, Office of the Spokesman, Washington, D.C., June 17, 2008, http://merln.ndu.edu/archivepdf/iran/State/105992.pdf.

41 “Majlis Votes to Slow Down Process of Entering WTO," Iran Times, December 3, 2010, p. 5.
} 
effect of the regime's dismissal of such offers is that the United States and its allies often see little choice but to rely heavily on costs going forward.

Although the history is discouraging, it is possible that these or other potentially valueenhancing items could be made more credible and attractive, especially if Iran's no-deal option worsens. Thus far, this has not proven to be the case. It is worth noting that such incentives are directed not only at Iranian negotiators. Highlighting genuine willingness to offer broader benefits, as well as to impose costs, is in part intended to send a message to Iranians beyond the hard-line regime as well as to non-Iranian parties whose full cooperation is valuable to this strategy.

\section{Assessment of Past U.S. Efforts via the Framework}

Given that the administrations of both President George W. Bush and President Barack Obama, in concert with other nations, have employed costs and incentives in combination, as well as different diplomatic approaches to the negotiations, the question arises of why neither was (to date) able to negotiate successfully with Iran, directly or tacitly. Or, more fundamentally, did a ZOPA exist or was one created that would permit a successful negotiation? The analytical framework introduced above can provide some insight into this question.

\section{BUSH ADMINISTRATION}

The public revelation of clandestine Iranian nuclear facilities at Natanz and Arak in 2002 led to significant international focus and action on Iran's nuclear weapons program. The resulting pressure was amplified by the U.S. invasion of Iraq in 2003, which left Iran effectively surrounded by U.S. forces. Iran subsequently entered negotiations with the "EU3" - France, Germany, and the United Kingdom — which resulted in a series of agreements according to which Iran agreed to suspend uranium enrichment (but not, ultimately, to give it up indefinitely). 
While the pressures on Iran were accumulating, the Bush administration's position appears to have been hardening. Although the United States and Iran warily cooperated with each other regarding Afghanistan in 2001,42 there was a widespread perception — in part resulting from Washington's refusal to participate in the EU3's negotiations - that by 2003 the United States was more interested in "regime change" in Iran than in a negotiated nuclear agreement. Thus, Iran's red line may have been moving downward (implying greater Iranian nuclear flexibility) as a result of the costs imposed by increased international diplomatic pressure and the palpable threat of U.S. military attack, but at the same time the U.S. red line appears to have been moving rightward (becoming more demanding) — or at least Iran and others perceived it to be so - dampening the potential for a ZOPA to be created. Whether or not there was a ZOPA at this time ultimately remained untested, as no formal U.S.-Iran negotiations took place.

By 2005, when the Bush administration agreed to join the EU3's negotiations with Iran on the condition that Iran suspend uranium enrichment prior to any talks, the pressure on Iran had decreased. Iran likely deemed the threat of U.S. attack to be significantly lower than in 2003; it had escaped to that point any meaningful penalties attending the revelation of its clandestine nuclear weapons efforts; and it had not been held to account for violating a series of agreements with the EU3 from 2003 to 2005. Furthermore, politics inside Iran had shifted with the replacement of the reform-minded President Mohammad Khatami with the then-obscure hard-liner Mahmoud Ahmadinejad. While pressure on Iran increased from 2005 to 2008 with the addition of Russia and China to what became the P $5+1$ coalition and the imposition of multiple rounds of sanctions, the pressure increased too slowly to compensate for the large gap between U.S. and Iranian red lines,

\footnotetext{
42 James Dobbins, “How to Talk to Iran,” Washington Post, July 22, 2007.
} 
likely preventing a ZOPA from opening. In any event, only one meeting on the nuclear issue with both the United States and Iran present was held, in Geneva in July 2008, and it yielded no progress.

\section{OBAMA ADMinistration}

On assuming the presidency, Barack Obama emphasized "engagement" with Iran, which sought to reassure Tehran that the United States was not intent on regime change but dedicated to a negotiated outcome to the nuclear dispute. Although not formally abandoned, the precondition that Iran suspend enrichment before talks with the United States, already weakened by U.S. attendance at the May 2008 P5+1 meeting with Iran, was further attenuated by President Obama's initiatives. The U.S. proposal of October 2009-to accept Iran's low-enriched uranium in return for highly enriched uranium necessary for fuel rods to produce medical isotopes in the Tehran Research Reactor-was widely seen as an indication that the United States was prepared to accept some Iranian enrichment activity, a perception reinforced by the P5+1's request in 2012 talks that Iran freeze only its higher-level enrichment. In addition, the declaration by President Obama and other senior U.S. officials that Iran having "a nuclear weapon" was the U.S. red line may have conveyed the impression to Tehran that nuclear progress short of that marker would be accepted by Washington, albeit grudgingly. The main effect of this diplomatic campaign was likely to shift Iran's perception of the U.S. red line leftward (i.e., that the United States was more flexible), explaining at least in part its willingness to return to formal negotiations in 2012.

In the process of reassuring Iran, however, the Obama administration likely diminished the credibility of a military attack as a threatened cost to Iran. Although President Obama and his top officials have for the most part maintained that the military option remains "on the table," senior Defense Department officials and others have been at pains to downplay the likelihood of a military 
attack, stressing its downsides in public remarks while publicly counseling Israel against an attack as well. ${ }^{43}$ The perception that the Obama administration had put aside the military option was reinforced by a public emphasis on containing a future nuclear-armed Iran, ${ }^{44}$ as well as by a reported Defense Department memo lamenting the White House's refusal to that point to allow serious consideration of even a modest military component to its Iran strategy. ${ }^{45}$ Thus even though the Obama administration has succeeded in securing serious new sanctions on Iran-and has subsequently begun visible military actions ${ }^{46}$ — the resulting pressure may have been weakened or counteracted by the diminished credibility of the U.S. military threat.

Just as domestic politics played a role in the U.S. shift, however, Iranian politics continued to harden the regime's positions on the nuclear issue. The June 2009 election turmoil likely put the regime in no mood to be conciliatory toward the West for fear of appearing weak or desperate, and may also have weakened Iranian Supreme Leader Khamenei's authority and thus his ability to make bold changes in policy. At the same time, dislike of President Ahmadinejad within conservative circles may have contributed to political fractiousness and the rejection by Tehran of the October 2009 fuel-swap deal. Regarding the analytical framework, then, the U.S. red line may have indeed been shifting leftward, but the combined effect of new sanctions and diminished military threat was ambiguous, while domestic considerations may have shifted Iran's red line upward. Thus, as during

\footnotetext{
${ }^{43}$ Feldman, "The Israeli Debate on Attacking Iran Is Over."

${ }^{44}$ See, for example, Hillary Rodham Clinton, "Townterview Hosted by Suttichai Yoon and Veenarat Laohapakakul of World Beat" interview, Bangkok, July 22, 2009, http://www.state.gov/secretary/rm/2009a/july/126335.htm. 45 David Sanger and Thom Shanker, "Gates Says U.S. Lacks a Policy to Thwart Iran," New York Times, April 17, 2010.

${ }^{46}$ See, for example, Sanger and Schmitt, "To Calm Israelis, U.S. Offers Ways to Restrain Iran."
} 
President Bush's time in office, during President Obama's tenure to date some factors have moved in favor of creating a ZOPA, but others have militated against it.

\section{Conclusion}

This study has sought to develop an analytic framework by which to assess a fundamental question potentially underlying the failure of the Iran nuclear negotiations over several years: while mistrust, misperception, and flawed diplomacy may play roles, does a mutually acceptable deal even exist? To assess this possibility, a negotiation analytic framework conceptually disentangles two issues: (1) whether a feasible deal exists and (2) how to design the most promising process to achieve one. Focusing on the first of these questions, whether a "zone of possible agreement" exists, this study has developed a graphical negotiation analysis-open to a wide range of policy assumptions - that precisely relates input assumptions about the parties' interests, their no-deal options, and possible deals, as well as the effects of cost-imposing and value-enhancing measures.

A full audit of the barriers standing in the way of a nuclear agreement between Iran and the United States would turn up a multitude of issues. Among them would certainly be mutual distrust arising from thirty years of estrangement and hostility, paucity of official contact or communication, the politics in both the United States and Iran over the two countries' fraught relationship, the radical ideology and political fractiousness of the Iranian regime, as well as poor negotiating tactics and missed opportunities by both sides.

Various efforts, both official and unofficial, have rightly been made to address these and other barriers to U.S.-Iranian rapprochement. Yet, the failure by multiple parties via a variety of negotiating processes to make serious progress toward a sustainable nuclear agreement with Iran suggests a deeper cause - the absence of any underlying zone of possible agreement. Simply put, a 
wide gulf apparently stands between the least nuclear capability the Iranian regime is willing to accept and the most nuclear capability the United States is prepared to concede to Iran. No combination of costs and incentives yet put forward has apparently matched the value that the regime likely sees as its no-deal option - a nuclear weapons capability or actual weaponization.

If indeed there is no ZOPA, a central focus on diplomatic processes or tactics is misplaced. Rather than tweaking the design of the deal offered to Iran — for example, by adjusting the phases and what is offered in each - U.S. policymakers and negotiators should consider as their most urgent priority influencing the "setup" in order to create and widen a ZOPA. It makes little sense to float this or that proposal - much less make one's best or bottom-line offer on nuclear-related issues - without confidence that the ground has been prepared for negotiations to succeed. Instead, it makes much more sense to use diplomacy to develop a better understanding of the other side that will help open or widen a ZOPA.

Creating a zone of possible agreement requires moving beyond fixations with one tactic or class of moves — for example, sanctions, military maneuvers, or engagement — without regard to the net effect on a ZOPA of the full range of policy actions. Instead, it requires that costs, incentives, and red lines be combined consciously as elements of a strategy to create a ZOPA that is simultaneously better for both sides than acquiescence or attack. This is the purpose of the analytical framework laid out above - to provide a tool for putting deliberate assessments of the distinct elements of the nuclear negotiations in proper analytic relationship to each other in order to draw valid conclusions and develop policy options. To accomplish this, policymakers should take the following four steps. 
First, in a disciplined and systematic manner, assess the Iranian regime's interests and perceptions of its no-deal options. It is remarkable that, more than thirty years after the rupturing of U.S.-Iran relations, little consensus exists among foreign policy analysts and practitioners regarding Iran's interests and ambitions; by the same point in the existence of the Soviet Union, George Kennan had already written his authoritative work on the "sources of Soviet conduct." 47 Cataloguing Iranian interests and perceived no-deal options requires robust, high-quality information and interpretations on the dynamics and deliberations of the Iranian regime. To the extent such information (and therefore sound assessments) is lacking, the United States and its likeminded partners should seek out or develop new channels for obtaining it.

Second, in a disciplined and systematic manner, determine U.S. interests and no-deal options. U.S. interests that would be affected by an Iranian nuclear weapons capability are relatively uncontroversial, but a clear understanding of U.S. no-deal options and red lines requires early and active consultation with domestic parties such as Congress and coalition partners.

Third, in a disciplined and systematic manner, catalog and rigorously assess all available levers - both incentives (value-enhancing provisions embodied in potential agreements) as well as cost-imposing measures. Carefully judge their credibility, relevance to actual Iranian regime interests, and magnitude relative to Iranian no-deal options of each possible measure, as well as to the cost to the United States of deploying the measure. Further, the impacts of such measures on coalition partners and other unrelated parties and interests should be part of the evaluation. Ideally, creative agreements can embody high-value, low-cost moves that result in joint benefit.

47 X (George F. Kennan). “The Sources of Soviet Conduct.” Foreign Affairs, Vol. 25, No. 4 (July 1947), pp. 566582. 
In particular, careful assessment of these distinct elements of the nuclear negotiations will help to provide a sharper answer to the issue of whether a ZOPA exists, and, if so, its most likely location. This assessment will not provide a single policy prescription. Rather, it will permit policymakers and analysts to move beyond bumper-sticker policy assertions in favor of or against engagement, sanctions, military actions, confidence-building measures, and the like. This will help to illuminate the multiple policy strategies — that is, sets of policy choices that together advance a particular goal - that can open a zone of possible agreement and permit the negotiations to succeed.

Fourth, to the greatest extent possible, take coordinated action involving the full set of policy levers to create and widen a ZOPA. Conceptually, as this article illustrates, there are two ways to create or expand a ZOPA. First, the United States could relax its own red line, as US officials appear to have done in recent years, by acquiescing in a hitherto rejected outcome or deal. Of course, the United States should not seek a nuclear agreement for its own sake, only one that is genuinely better for U.S. interests than either war or acquiescence to a nuclear Iran. By drawing the line at Iran not having "a nuclear weapon," rather than a nuclear weapons capability, and by acquiescing to some uranium enrichment by Iran, the United States has begun to entertain deals that previously would have been judged worse than its no-deal option of military conflict. But, without a persuasive explanation by U.S. officials as to why accepting a "more nuclear" Iran is less damaging to U.S. interests than previously concluded, or why on the other hand Washington's nodeal option of military conflict is more damaging to those interests, the Obama administration risks a situation in which it allows Iran to perceive a flexibility or irresolution in the U.S. position that 
may not exist either with the current administration or because future administrations, the U.S. Congress, or U.S. allies will not accept the resulting deal.

With respect to the analytical framework presented here, this dilemma clearly illustrates the difference between negotiating tactics and the underlying negotiation "setup." By taking a conciliatory tone and offering "face-saving" deals to Iran, U.S. officials may hope to jump-start negotiations. But if at the same time they give Tehran the impression that the U.S. red line is to the left of its actual location (implying greater U.S. nuclear flexibility in this article's graphical representation), it would give Iran a false impression of the location of a ZOPA. The perverse result would be that Iran could believe that negotiations are succeeding when the United States believes they are failing, leading to a conflict that might have been prevented had the United States been clearer and firmer about its red lines and provided Tehran with a more accurate sense of the ZOPA.

Instead of making changes to US red lines that are not advisable, or hinting at flexibility that does not actually exist, the United States should emphasize expanding the ZOPA by wielding costimposing and value-enhancing measures effectively in concert. This sounds deceptively straightforward; it is anything but. As discussed above, both costs and incentives must meet three criteria. First, they must be credible. Yet until recently, the United States (and Israel) has consistently undercut perhaps its most effective means of pressure - the threat of military force by downplaying that threat, failing to take visible measures to increase its credibility, and publicly fretting about its effectiveness and downsides. Whatever those downsides may be, emphasizing them publicly is counterproductive in terms of influencing the Iranian regime's perception of the costs of no-deal. 
Costs and incentives must also be meaningful for the Iranian regime's interests rather than a box-checking exercise. Many of the sanctions imposed on Iran had little impact on the regime's core interests, until recent measures targeting its oil export revenues and access to the international financial system were enacted. For a regime concerned about survival, increased support for its domestic opposition might also prove a powerful motivation to change course. With respect to incentives, the Iranian regime likely places little value on many of the items offered by the United States such as WTO membership or improved diplomatic relations.

Finally, such measures must be of sufficient magnitude relative to the value Iran places on its nuclear program; we can surmise that this value is very high, given the enormous sacrifices the regime has endured to sustain the program. This may be the criterion on which U.S. actions have fallen most significantly short. Sanctions have been applied sporadically and in increments. The tendency to focus on the marginal effect of each measure - rather than on the overall effect on the ZOPA of all such measures - has hamstrung U.S. efforts to create the conditions necessary for a negotiated agreement. It also reflects a broader tendency to focus on costs and incentives individually, rather employing them in concert as elements of a strategy to open a ZOPA.

If, as seems likely based on our relatively limited analysis under mainstream policy assumptions, the Iranian regime's no-deal option thus far appears superior (from its perspective) to the agreements on offer, a ZOPA may not exist at present. The absence of a ZOPA would pose an insurmountable barrier to agreement that would defeat all tactical and process-oriented initiatives. To open space for a worthwhile nuclear deal—one that avoids both military conflict and a nucleararmed Iran-the United States should embrace a relentless and creative strategy to worsen Iran's no-deal options while demonstrating the value of a "yes" to the regime as well as to the broader 
Iranian populace. This requires a firm red line, clearly communicated; costs and incentives that are credible, meaningful, and of sufficient magnitude; and the wherewithal to combine these disparate elements of policy into a coherent strategy to create and expand a ZOPA.

Without an underlying zone of possible agreement, a primary focus on negotiation process and tactics - getting the right tone, venue, communication style, framing, level of secrecy, use of back channels or third parties, and so on—cannot work. However, if tough, skillful diplomacyincluding, if necessary, the credible threat of force-succeeds in opening and widening a zone of agreement, the sophisticated use of these and other process tools will be key to reaching a worthwhile agreement. If no zone of possible agreement can be created despite these efforts, then the policy focus necessarily must shift to the tough choices among nonnegotiated options. 